\title{
Implementation of real-world class activities in an Introduction to Environmental Engineering Class
}

\section{Dr. Cara J Poor P.E., University of Portland}

Dr. Poor teaches many of the integral undergraduate civil engineering courses at University of Portland, including hydraulics, fluids, and environmental engineering. Dr. Poor is a licensed professional engineer with ongoing research in green infrastructure design, water quality, watershed management, and engineering education. She is currently developing new curricula for hydraulics, fluids, and environmental engineering labs, and conducting research on methods to improve conceptual understanding and critical thinking.

\section{Dr. Heather Dillon, University of Portland}

Dr. Heather Dillon is an Associate Professor in Mechanical Engineering at the University of Portland. Her research team is working on energy efficiency, renewable energy, fundamental heat transfer, and engineering education. Before joining the university, Heather Dillon worked for the Pacific Northwest National Laboratory (PNNL) as a senior research engineer.

\section{Jeffrey Matthew Welch, University of Portland}

Jeff Welch is a doctoral student in educational leadership at the University of Portland (Oregon, USA).

\section{Dr. Nicole C. Ralston, University of Portland}

Dr. Nicole Ralston is an Assistant Professor and co-Director of the Multnomah County Partnership for Education Research (MCPER) in the School of Education at the University of Portland in Portland, Oregon. She received her Ph.D. in Educational Psychology with an emphasis in Measurement, Statistics, and Research Design from the University of Washington. An elementary school teacher at heart, she now teaches educational research and STEM methods to undergraduate and graduate students. Her research focus involves bringing active learning strategies to STEM, best practices of research-practice partnerships, and applied research in partnership. 


\section{Implementation of real-world class activities in an Introduction to Environmental Engineering Class}

\section{Introduction}

The traditional focus in introductory environmental engineering classes has been on technical content, with a reliance on simple book problems similar to examples the instructor does in class $^{1,2,3,4,5}$. Many graduates are not able to easily apply the technical knowledge they gained in school to professional practice ${ }^{5}$. Students need experience solving real-world problems in order to be successful after graduation. There is a need for students to have experience solving more practical, real-world problems similar to what they will experience in the workplace ${ }^{5,6,7}$. In addition, there is a need for students to be more aware of the social, environmental, and economic aspects of design and decision-making ${ }^{1,2,5,8}$. In professional practice, design decisions should be made not merely based on the best available technology, but also on how the design will impact society and the surrounding environment.

Most studies in environmental engineering education focus on implementing sustainability modules or activities in environmental engineering classes ${ }^{9,10,11,12,13}$. Others have focused on open-ended lab activities ${ }^{14}$ and taking an interdisciplinary approach to environmental engineering instruction ${ }^{15}$. Studies are needed on applying real-world problems in environmental engineering classes to ensure students are successful in engineering practice.

All civil engineering students, not just those going into the environmental engineering profession, need to have a basic knowledge of environmental issues and how to make designs more sustainable. In the age of climate change and environmental disasters (e.g., 2019-2020 bushfires in Australia, 2011 earthquake in Japan that caused a massive release of radioactive material, 2010 Deepwater Horizon oil spill in the Gulf of Mexico), it is important for all engineers to be aware of how they can help minimize, avoid, and/or solve these problems. Solving many of today's environmental problems will require future engineers to be creative, cooperative, and have an entrepreneurial spirit ${ }^{3,4}$. This starts with learning about and working on solutions to real-world problems in the classroom.

The Kern Entrepreneurial Engineering Network (KEEN) is a group of faculty working to help engineering students develop these critical skills ${ }^{16}$. One facet of the KEEN framework is helping students connect engineering concepts with real world systems. The class activities described in this paper were developed in part using this framework as a starting point for the learning objectives.

To provide an opportunity for students to have knowledge of and experience with real-world problems, two class activities were developed. One activity was focused on access to clean drinking water and chemical equilibrium, and the other activity was focused on low oxygen levels in rivers and the oxygen sag curve.

\section{Methodology}


Students worked in groups of two to complete each class activity. The majority of the work for each class activity was completed during an 85-minute class session, and students spent additional time outside of class summarizing their results in a technical memorandum. At the end of the semester, students completed a survey to evaluate the efficacy of the class activities. To address the need to for civil engineering students to make connections between technical knowledge gained in school and professional practice ${ }^{5}$, to use information beyond what is found in the textbook ${ }^{1,2,3,4,5}$, and to learn environmental engineering in the context of real-world problems ${ }^{5,6,7}$, the following objectives were developed for the class activity:

1. Identify and evaluate sources of information

2. Connect life experiences with course content

3. Identify real world engineering opportunities and constraints

4. Identify links between course knowledge and real world systems

Class Activity Development. Activities were focused on two common environmental issues: access to clean drinking water and low oxygen levels in rivers. These two issues were also selected due to students' struggle with chemical equilibrium equations and the oxygen sag curve in previous classes. Activities were developed so students had to find information on the internet, use the information to make calculations using equations provided in class, conduct research on current technology, and recommend potential solutions. This provided an opportunity for students to use equations in a practical application.

The first activity was focused on access to clean drinking water. Billions of people still lack access to safe, clean water. Although many treatment methods have been developed recently to improve access (i.e., Life Straw, Solar Water Disinfection), young Environmental Engineers should be aware and looking for additional solutions. The following problem statement was given on the activity:

Many people in developing countries do not have access to clean drinking water. According to the World Health Organization (WHO), 2.1 billion people (or 3 in 10 people worldwide) lack safe drinking water at home ${ }^{17}$. 263 million people spend over 30 minutes per trip collecting water, and 159 million drink untreated water from streams, lakes, and watering holes. Drinking contaminated water has been linked to diseases such as cholera, dysentery, hepatitis A, typhoid, and others.

The students had to answer the following questions:

1. One way to disinfect contaminated drinking water is to add bleach. How much bleach needs to be added to $1 \mathrm{~L}$ of water at a $\mathrm{pH}$ of 6.5 for proper disinfection?

2. What are the societal and economic impacts of lacking access to clean drinking water?

3. What are other ways people can disinfect their drinking water?

Students then summarized their results and findings in a technical memorandum. A class discussion of societal and economic impacts of a lack of access to clean drinking water, and potential solutions occurred at the beginning of the next class period. 
The second activity was focused on low oxygen levels in rivers. Low oxygen levels due to algal blooms and/or toxic algae have become increasingly common. Large algal blooms and fish kills (due to low oxygen levels) have occurred in many water bodies, which negatively impacts the aquatic ecosystem and disrupts the ability for municipalities to supply safe, clean drinking water. In 2018, the water supply for the City of Salem, OR was disrupted due to a toxic algal bloom in Detroit Lake ${ }^{18}$. Residents were not able to safely drink the water until an emergency treatment system was constructed. The City of Toledo, $\mathrm{OH}$ has also experienced a disruption in water supply in 2011 and 2014 due to toxic algal blooms in Lake Erie ${ }^{19}$. Since this is an emerging problem, it is important for Environmental Engineering students to be aware of it. The following problem statement was given on the activity:

Due to recent algal blooms in Detroit Lake, fish kills have been observed in the North Santiam River. The North Santiam River is home to trout, whitefish, and endangered salmon and steelhead. Fish kills occur due to oxygen being consumed by algae-degrading bacteria faster than oxygen can diffuse into the water. If oxygen levels get too low (below $2 \mathrm{mg} / \mathrm{L}$ ), many fish species can no longer survive in the river.

The students had to answer the following questions:

1. At what distance downstream from Detroit Lake will oxygen be at the lowest levels?

2. What is the lowest oxygen level in the North Santiam River?

3. What caused the algal bloom?

4. What are possible solutions that will increase oxygen to acceptable levels? Evaluate each alternative based on impact to the surrounding ecosystem, cost, sustainability, and time required for implementation.

5. What is your recommended solution? Discuss rationale for your recommendation.

Similar to the first activity, students then summarized their results and findings in a technical memorandum. A class discussion of recommended solutions occurred at the beginning of the next class period.

Evaluation of Class Activities. The activities were evaluated in an Introduction to Environmental Engineering class Spring 2019, a required sophomore level civil engineering course. There were 22 students in the class. Lectures and in-class assignments on chemical equilibrium, including acid-base reactions, occurred before the "access to clean water" activity. In-class assignments included acid-base problems where students calculate $\mathrm{pH}$ or constituent concentrations using equilibrium equations. Lectures and in-class assignments on the oxygen sag curve and StreetorPhelps equation occurred before the "low oxygen levels in rivers" activity. In-class assignments included problems where students calculate critical time/distance and minimum dissolved oxygen levels using the Streetor-Phelps equation.

At the end of the semester, students completed a survey evaluating their ability to meet the following objectives for the class:

1. Identify and evaluate sources of information

2. Connect life experiences with course content 
3. Identify real world engineering opportunities and constraints

4. Identify links between course knowledge and real world systems

Students were also asked to provide a specific example of how their ability improved as a result of the class. This was an indirect way of evaluating the class activities; students were not explicitly asked about the activities. Other assignments in the class included problems from the textbook, and practice problems similar to the textbook problems. Other than discussing environmental issues during lecture, the activities were the only chance to complete the four objectives listed above and for students to obtain experience working on real-world problems. To evaluate their specific example (qualitative results) for each objective, qualitative pattern coding was utilized to identify patterns and themes within the responses ${ }^{20}$.

In the survey, students were given varying degrees of agreement or disagreement on a Likert scale, and asked to circle which best represented their opinion:

$\begin{array}{ll}5 & \text { Strongly Agree } \\ 4 & \text { Somewhat Agree } \\ 3 & \text { Neutral } \\ 2 & \text { Somewhat Disagree } \\ 1 & \text { Strongly Disagree }\end{array}$

The Likert scale used for the survey is very useful in this type of application and has been effective in many educational applications ${ }^{21}$. Although student self-report bias is a concern for these types of surveys, this study allowed students to complete the survey anonymously and the survey administrator made clear that their survey responses would in no way affect their grade. To evaluate the difference between questions, the Pearson's product moment correlation coefficient was calculated based on a linear relationship in $\mathrm{R}^{22}$. Differences between responses for each objective were evaluated using the Tukey honest significance difference method in $\mathrm{R}^{23}$.

\section{Results and Discussion}

Overall, students enjoyed the class activities and found value in them. Every student actively participated in gathering data and making calculations during class. The following sections summarize the survey results as well as student comments.

Survey Results. Figure 1 shows the survey results. Results indicate the majority of students believed the activities helped them identify real world engineering opportunities and constraints (4.57) and identify links between course knowledge and real world systems (4.64). Although not as strong of a response, students also thought the activities helped them identify and evaluate sources of information (3.61) and connect life experiences with course content (3.91). The response to the first objective, identifying links between course knowledge and real world problems, was rated statistically significantly higher $(\mathrm{p}<0.05)$ compared to the other objectives. Correlations between survey questions (and learning objectives) were all low, -0.1 to 0.3 . Students appeared to appreciate the connection between real problems and what they are learning in class. 
Ability to identify and evaluate sources of information

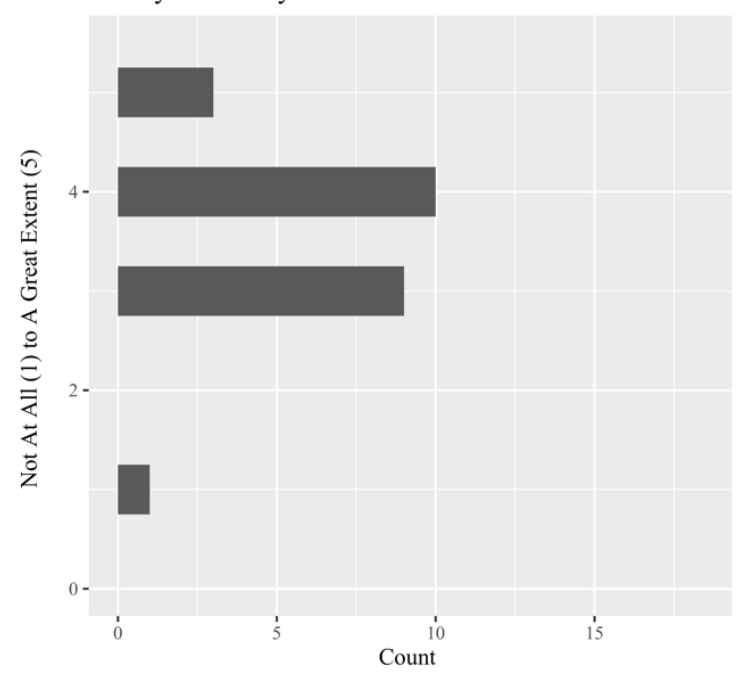

Identify links between course knowledge and real world

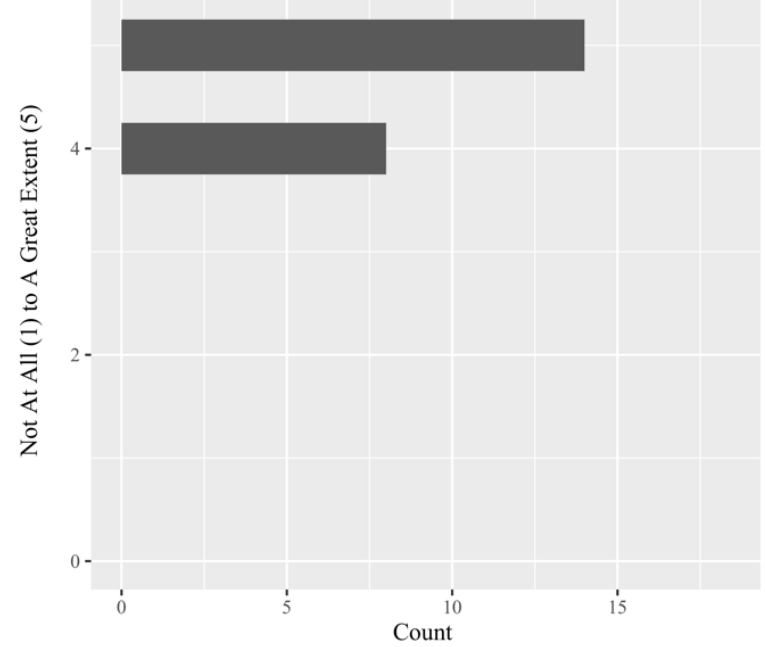

Ability to connect life experiences with course content

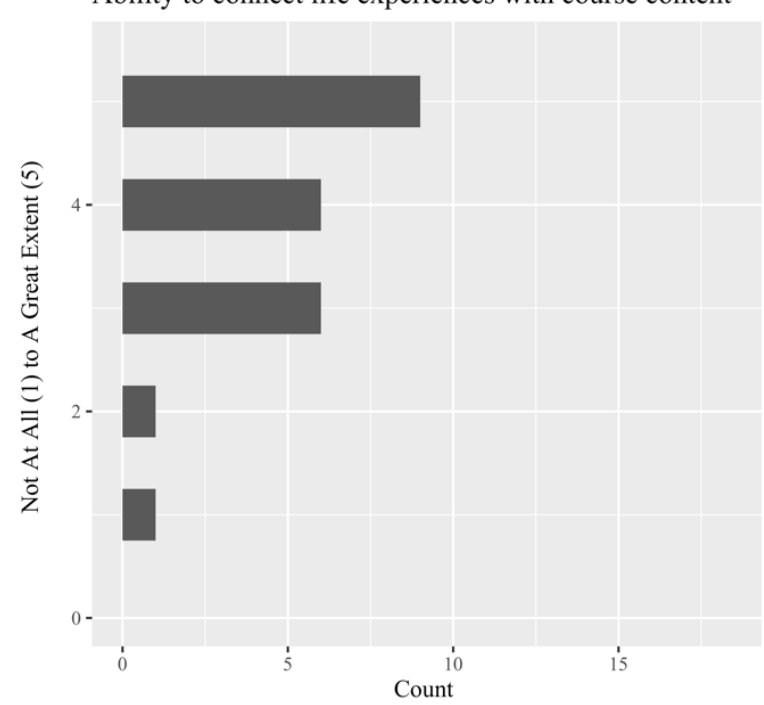

Identify real engineering opportunities and constraints

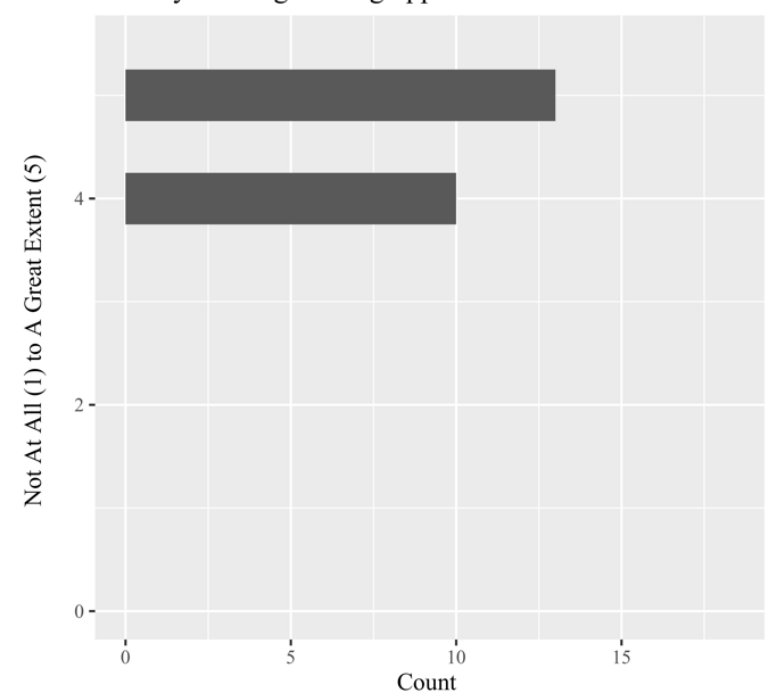

Figure 1. Survey results for Spring 2019 Introduction to Environmental Engineering Class.

Student Comments. Student comments were very positive. The majority of students were able to provide specific examples of how their ability to achieve the objectives improved due to the class. Although comments were not all related to the activities, students still mention how useful activities were.

1. Identify and evaluate sources of information: The majority of students $(70 \%)$ were able to provide a specific example of identifying and evaluating sources of information. Below is a sampling of student responses:

- "Looking for sources for memos, I had to analyze which sites were credible, which helped me identify proper sources." 
- "I have truly gained the ability to identify and evaluate sources from several in class memos."

- "In this class, we completed exercises by finding outside sources. For example, we had to find articles that described what caused the algal bloom in a lake and provided information on how to fix the contamination."

All of these comments are in relation to the class activities, which indicates student ability increased due to the activities.

2. Connect life experiences with course content: $61 \%$ of students were able to provide a specific example of connecting life experiences with course content. Below is a sampling of student responses:

- One major connection I made involved algal blooms in lakes due to phosphorous. Being from Washington, I had heard a lot about algal blooms but didn't understand why until this course.

- This class helped me to connect life experiences with course content mostly when we went on the field trip. I was able to see that we were doing in class was essentially similar to what they do in the field.

One of these comments are in relation to the class activities, and one is in relation to a field trip we took in the lab class (not part of CE 367). It appears that although the majority of students thought their ability to connect life experiences with course content, it may not have been solely due to the class activities.

3. Identify real world engineering opportunities and constraints: Almost all of the students (91\%) were able to articulate a connection between class material and real world engineering opportunities. Only $35 \%$ were able to identify a specific constraint that applied to a real-world situation. The lower number is likely due to the activities; students were required to identify opportunities or potential solutions, but were not asked to evaluate constraints. Future iterations of the activities will require students to evaluate economic, political, and societal constraints to potential solutions. Below is a sampling of student responses:

- "I would say this class opened up my eyes to actually connecting an engineering work to the real world, specifically environmental engineering. An example is a wastewater treatment plant. Designing one is a great opportunity while things like deteriorating pipes may be a constraint."

- "We often discuss issues that have occurred in the engineering world and learn how money, politics, and environmental impacts all play a role in what happens. Therefore it is interesting to know what issues are affecting the engineering process and where things are going right." 
Although these comments do not address the activities specifically, it is clear that students have an appreciation for practical applications and engineering opportunities. The class activities likely contributed to their appreciation.

4. Identify links between course knowledge and real world systems: $87 \%$ of students stated there was a connection between coursework and real world systems, and $70 \%$ were able to identify a specific example of a real-world application of course knowledge. Below is a sampling of student responses:

- "The connections between settling velocity and the visit to the wastewater treatment plant to see the implementation of a settling tank was most useful to see the real world applications."

- "For example, when we studied wastewater treatment in class, I understood the concepts. After seeing it in real life and connecting the live experience vs. the class work, I felt like it helped a lot to understand use."

○ "In this class we look at a lot of real-world examples and the lab supplement is very helpful in connecting the material we learn in class to real-world examples."

Comments appear to focus on the lab class and field trip to the wastewater treatment plant, not the class activities. Although the class activities likely contributed to their understanding of the links between course knowledge and real world systems, students did not believe it was the main reason for their increased ability to identify the links.

Although survey results indicate students appreciated the activities and found value in them, overall test scores on chemical equilibrium and oxygen sag curves did not change compared to the previous years' class. This indicates the activities did not improve understanding of these concepts, but may have improved value and contextual setting.

\section{Conclusions}

Results indicate that the two class activities improved students' ability to make the connection between what they learn in class and real-world problems. The strong results for making connections confirms that this is a promising approach for helping students build an entrepreneurial mindset in environmental engineering. Although the activities may not have improved understanding of chemical equilibrium and oxygen sag curves, qualitative results suggest that students have a better understanding of their application. As a result, the activities add value to the class. Future iterations of the class activities will include a task for evaluating constraints, and asking students to make additional calculations to help improve their understanding of concepts.

\section{Acknowledgements}

The funding for this work was provided by the Kern Engineering Education Network (KEEN) as part of a grant to the University of Portland. 


\section{References}

1. Hyde, R.A., and Karney, B.W. (2001). Environmental Education Research: Implications for Engineering Education. Journal of Engineering Education 90(2): 267-275.

2. Rugarcia, A., Felder, R.M., Woods, D.R., and Stice, J.E. (2000). The Future of Engineering Education I. Vision for a New Century. Chemical Engineering Education 34(1): 16-25.

3. Felder, R.M., Woods, D.R., Stice, J.E., and Rugarcia, A. (2000). The Future of Engineering Education II. Teaching Methods That Work. Chemical Engineering Education 34(1): 26-39.

4. Grasso, D., Callahan, K.M., and Doucett, S. (2004). Defining Engineering Thought. International Journal of Engineering Education 20(3): 412-415.

5. Mills, J.E., and Treagust, D.F. (2003). Engineering Education - Is Problem-based or Project-based Learning the Answer? Australasian Journal of Engineering Education 2(2): 2-16.

6. Bhandari, A. and Erickson, L.E. (2005). Case Studies Can Fill a Critical Need in Environmental Engineering Education. Journal of Environmental Engineering 131(8): 1121.

7. Nair, I., Jones, S., and White, J. (2002). A Curriculum to Enhance Environmental Literacy. Journal of Engineering Education 91(1): 57-67.

8. Broman, G.I., Byggeth, S.H., and Robert, K. (2002). Integrating Environmental Aspects in Engineering Education. International Journal of Engineering Education 18(6): 717-724.

9. Watson, M.K., Noyes, C., and Rodgers, M.O. (2013). Student Perceptions of Sustainability Education in Civil and Environmental Engineering at the Georgia Institute of Technology. Journal of Professional Issues in Engineering Education and Practice 139(3): 235-243.

10. Bielefeldt, A.R. (2011). Incorporating a Sustainability Module into First-Year Courses for Civil and Environmental Engineering Students. Journal of Professional Issues in Engineering Education and Practice 137(2): 78-85.

11. Glavic, P. (2006). Sustainability Engineering Education. Clean Technologies and Environmental Policy 8: $24-$ 30.

12. Mihelcic, J.R. and Philips, L.D. (2006). Integrating a Global Perspective into Education and Research: Engineering International Sustainable Development. Environmental Engineering Science 23(3): 426-438.

13. Murphy, C.F., Allen, D., Allenby, B., Crittenden, J., Davidson, C.I., Hendrickson, C., Matthews, H.S. (2009). Sustainability in Engineering Education and Research at U.S. Universities. Environmental Science and Technology 43(15): 5558-5564.

14. Flora, J.R.V. and Cooper, A.T. (2005). Incorporating Inquiry-Based Laboratory Experiment in Undergraduate Environmental Engineering Laboratory. Journal of Professional Issues in Engineering Education and Practice 131(1): 19-25.

15. Semerjian, L., El-Fadel, M., Zurayk, R., and Nuwayhid, I. (2004). Interdisciplinary Approach to Environmental Education 130(3):

16. Kern Entrepreneurial Engineering Network (KEEN) (n.d.). KEEN - The Framework. $<$ https://engineeringunleashed.com/mindset-matters/framework.aspx $>$ Accessed 01/16/2020.

17. World Health Organization (WHO) (2019). Drinking Water. < https://www.who.int/news-room/factsheets/detail/drinking-water> Accessed 02/05/2019.

18. Carpentar, K.D., and Rounds, S. (2019). Harmful Algal Blooms and Drinking Water in Oregon. Oregon Water Science Center News, USGS. <https://www.usgs.gov/centers/or-water/science/harmful-algal-blooms-anddrinking-water-oregon?qt-science_center_objects=0\#qt-science_center_objects $>$ Accessed 01/08/20.

19. Dybas, C. (2019). Lake Erie's Toxic Algae Blooms: Why is the Water Turning Green? National Science Foundation News. <https://phys.org/news/2019-04-lake-erie-toxic-algae-blooms.html > Accessed 01/08/20.

20. Saldana, J. (2015). The Coding Manual for Qualitative Researchers. Sage Publications, Thousand Oaks, CA.

21. DeVellis, R.F. (2003). Scale Development, Theory and Applications, Second Edition. Applied Social Research Methods Series, Volume 26. Sage Publications, Thousand Oaks, CA.

22. R documentation (n.d.). The Pearson Product Moment Correlation Coefficient, $<$ https://www.rdocumentation.org/packages/SuppDists/versions/1.1-9.5/topics/Pearson> Accessed 03/09/2020.

23. R Documentation (n.d.). Tukey Honest Significant Differences. $<$ https://www.rdocumentation.org/packages/stats/versions/3.6.2/topics/TukeyHSD> Accessed 01/16/2020. 